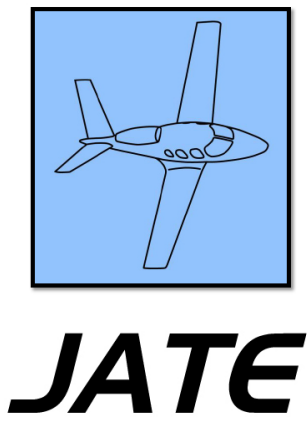

Journal of Aviation Technology and Engineering 7:1 (2017) 66-75

\title{
Safety Climate of Ab-Initio Flying Training Organizations: The Case of an Australian Tertiary (Collegiate) Aviation Program
}

\author{
Yi Gao and Natalia Rajendran \\ Swinburne University of Technology (Australia)
}

\begin{abstract}
A healthy safety culture is essential to the safe operation of any aviation organization, including flight schools. This study aimed to assess the safety climate of an Australian tertiary (collegiate) aviation program using a self-constructed instrument. Factor analysis of the instrument identified four safety themes, which are Safety Reporting Culture, Safety Reporting Procedure, Organizational Culture and Practice, and General Safety Knowledge. The responses of student pilots suggested that the overall safety climate of the subject flight training academy was healthy at the time of the survey. Further analyses found that perceptions of students of different year groups on Reporting Culture and Organizational Culture and Practices were significantly different from each other, with the first-year students responding more positively. Besides addressing the safety climate of the subject flight training academy, this study also provided a template and a benchmark for other tertiary (collegiate) aviation programs to assess their own safety climate.
\end{abstract}

Keywords: safety climate, safety culture, factor analysis, tertiary aviation, collegiate aviation

\section{Introduction}

Safety culture, which can be interpreted as "an enduring and stable concept defined at the group level or higher that refers to the shared values among all the group members and emphasizes the contribution from everyone at every level of an organization" (Gao, Bruce, Newman, \& Zhang, 2013), is related to a similar term, safety climate, which can be viewed as "the temporary state of safety culture" (Wiegmann, Zhang, von Thaden, Sharma, \& Mitchell, 2002). In brief, safety climate can be interpreted as a "snapshot" of the safety culture at a given time. It has been found in previous studies that safety practice/performance of an organization is positively correlated to the safety culture of that organization (Kao, Stewart, \& Lee, 2009; Niskanen, 1994; Varonen \& Mattila, 2000), which explains the sheer amount of literature on safety culture and safety climate in various domains.

In aviation, most safety culture studies have focused on commercial aviation organizations. For instance, Gao et al. (2013) studied the safety climate of flight crew working for a commercial airline in the Asia-Pacific region and analyzed the effort of employment history in affecting employees' safety perception. Kao et al. (2009) surveyed the safety culture of flight attendants working for four major Taiwan national airlines and found that safety culture was a predictor of cabin safety outcomes. Ek and Akselsson (2007) assessed the safety culture of a ground handling company using a multiplex

All correspondence concerning this article should be directed to Yi Gao at ygao@swin.edu.au. 
approach method. And Ek, Akselsson, Arvidsson, and Johansson (2007) used questionnaires and interviews to study the safety culture of one administrative and two operative units in a Swedish air traffic control setting.

While a large amount of literature on organizational safety culture and safety climate is existent for commercial aviation organizations, studies with regards to flight training organizations are rather limited. Freiwald, Lenz-Anderson, and Baker (2013) used mixed methods (survey and interview) to study the attitudes and perceptions of both operations and management staff of a multinational, multicampus flight training organization. Their study found a lack of a safety culture within that organization, which had just experienced a string of aircraft hull losses. Adjekum (2014) used the Collegiate Aviation Program Safety Culture Assessment Survey (CAPSCAS) to assess the safety culture of an accredited Part 141 collegiate aviation program in the USA as part of the implementation of a safety management system. The study identified the effects of year groups and national culture on the perception of safety culture of the collegiate aviation program. Subsequently, Adjekum et al. (2015) adopted a updated version of the CAPSCAS to investigate how safety culture perceptions influenced safety reporting behavior by studying flight students of five collegiate aviation programs in the USA. Findings of their study suggested that the age of respondents and perceptions of reporting system and safety fundamentals could predict safety reporting behavior.

From the review of the literature above, it can be seen that most of the studies on safety culture and safety climate focused either on commercial aviation or American flight training organizations, and there are very few studies on flight training organizations outside of America. And due to the distinctive regulatory environment and management setup of flight training organizations of different countries, instruments that were used in previous studies could hardly be used before major modifications. Therefore, the motivations of this study are to examine the safety climate of an Australian tertiary (post-secondary) aviation program using a self-constructed instrument and to examine the effect of training experience as well as year groups of students on their perceptions of the safety climate. It was expected that the current study would enrich the existing literature on safety climate by introducing a new instrument and, more importantly, a process that could be easily adopted by organizations with limited resources to examine and to benchmark their own safety climate.

\section{Methods}

\section{The Aviation Program}

The aviation program being studied here sits within the university with which the authors are affiliated. The program is one of the few programs in Australia that is accredited to offer bachelor's degree as well as flight qualifications to students who want to pursue a professional career as pilots. The annual intakes of students range from 60 to 70 , and currently there are about 200 students active in the program. While academic units are being taught face-to-face on the metropolitan campus of the university, ground theory classes and flight training are provided by an external flight training academy in a partnership agreement. This study aimed to address the safety climate of the flight training academy where the actual flight training is conducted.

Before entering the program, students are selected by their secondary school academic results, interview performance, and computer-based pilot aptitude test results. For students who are successfully admitted to the program, they are expected to receive a Commercial Pilot License (CPL) and to complete a multi-crew cooperation and jet orientation course or Flight Instructor Rating while studying for their bachelor of aviation (single degree, 3 years) or bachelor of aviation/bachelor of business (double degree, 4 years).

\section{Survey Instrument}

The instrument used in this study to collect participants' perceptions of the safety climate of the flight training academy was tailored to the aims of the study, as there was not a ready-to-use instrument fitting the scope of this study. Using a self-administered instrument makes it possible to accurately address issues that are specific to the targeted aviation program, while it brings in challenges to compare findings with other studies.

The survey instrument is composed of two parts. Part I is about demographic information, which was designed to understand the survey participants and their progress in flight training. A total of six questions are included in this part. Part II of the survey instrument includes 35 items that were designed to examine the safety climate of students' training environment. Items Q7-Q41 deal with generic situations that students may come across in their daily training. Participants were asked to indicate their agreement, or disagreement, with these items on a five-point Likert scale ranging from "strongly agree" to "strongly disagree". Responses to survey items were scored so that lower scores represent agreement. For instance, 1 represents "strongly agree" and 5 means "strongly disagree". Mean responses less than 3 will be interpreted as skewness to agreement while mean responses higher than 3 represent disagreement. See Appendix A for details of the survey questionnaire.

\section{Data Collection}

Data collection occurred during 2-18 September 2015. Hard-copy questionnaires were distributed to students while they were taking ground theory classes in the flight training academy. Students were briefed about the voluntary nature of survey participation and they were well informed of their right of self-withdrawal at any stage of the 
survey without penalties. After completed questionnaires were collected, data were then transcribed into an electronic spreadsheet for subsequent analysis. Further validation had been conducted by a second researcher to ensure the accuracy of transcription.

\section{Data Analysis}

Exploratory factor analysis was used to analyze responses to Part II of the survey to determine if themes of safety climate were represented by the survey items. See Appendix B for the Pattern Matrix, Structure Matrix, Factor Correlation Matrix, and the Scree Plot of factor analysis. Subsequently a multivariate analysis of variance (MANOVA) was performed to test if there were significant differences between students of different flying hours, and between students from different year groups.

\section{Results}

A total of 105 survey questionnaires had been distributed, and 103 were collected back from participants. Among those returned responses, 100 were properly completed, resulting in an actual response rate of $95.24 \%$. The higherthan-normal response rate was partially due to the lecture environment in which data collection was conducted. Students in general were willing to participate in such activities during their normal lecture hours.

\section{Demographics}

Among the 103 participants, 87, or $84 \%$, were males and 16 were females (16\%). In terms of participants' age, $35 \%$ of them were aged 18-19 years, $43 \%$ were between 20 and 22 years, $13 \%$ were between 23 and 25 years, and $10 \%$ were over 25 years old at the time of the survey. As of the year groups, nearly half of the participants (48) were from the first year, 29 were from the second year, and 25 were from the third year. Participants were also asked about their flying experience and licenses they currently held; see Figures 1 and 2 for details.

\section{Exploratory Factor Analysis}

To ascertain if all responses to the 35 generic safety items (survey items Q7-Q41) in Part II were suitable to be factor analyzed, correlational analysis was conducted. Items Q7, Q8, Q19, Q22, and Q23 were removed from further analyses as they failed to have a significant correlation with any of the other safety items in the data set.

The remaining 30 items were subjected to a series of exploratory factor analyses (EFA) using SPSS Version 20. Prior to performing the analyses, the suitability of the data for EFA was assessed using a principal components analysis (PCA). Inspection of the correlation matrix revealed the presence of sufficient coefficients of 0.3 and above. The Kaiser-Meyer-Olkin value was 0.80, exceeding the recommended value of 0.60 (Kaiser, 1970, 1974), and Barlett's test of sphericity (Barlett, 1954) reached statistical significance, supporting the factorability of the correlation matrix.

The PCA revealed the presence of six components with eigenvalues exceeding 1 , explaining $33.72 \%, 10.99 \%, 7.77 \%$, $6.47 \%, 5.24 \%$, and $5.17 \%$ of the variance, respectively. However, an inspection of the scree plot (Figure 3, Appendix B) revealed a clear break after the fourth component (Catell, 1966). A four-factor solution was also supported by Velicer's minimum average partial test. Eleven items (items Q9, Q10, Q11, Q15, Q16, Q17, Q20, Q21, Q28, Q29, Q30) were eventually removed because they did not contribute to a simple factor structure for various reasons such as cross-loadings or not loading at all. The resultant measure comprised 19 of the original 35 items included in the survey instrument.

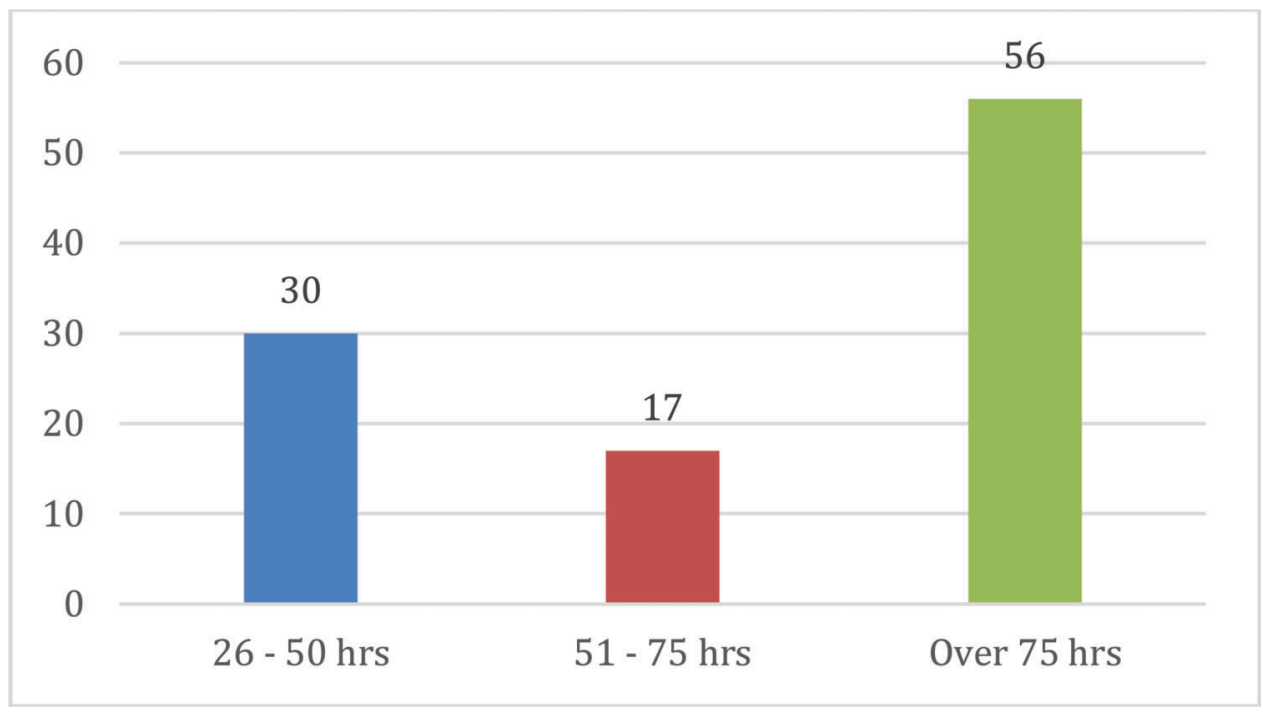

Figure 1. Survey participants' flying hours. 


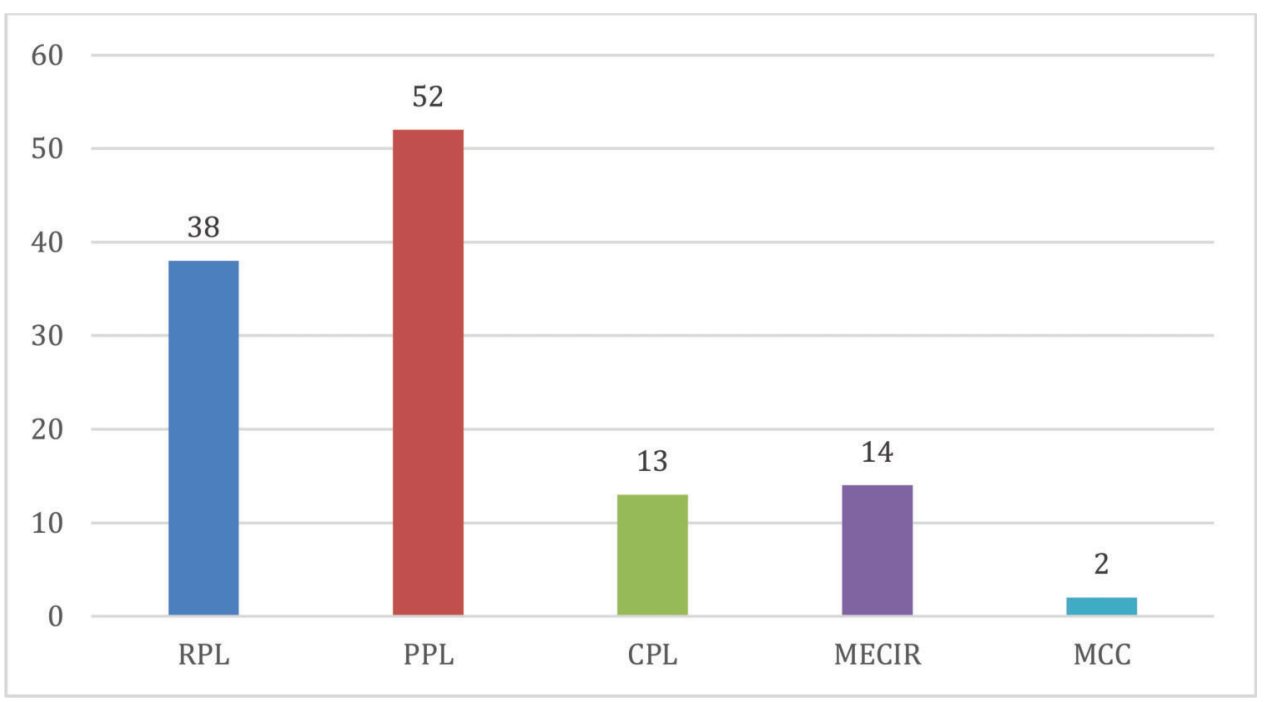

Figure 2. Current license/rating held. (RPL, Recreational Pilot License; PPL, Private Pilot License; CPL, Commercial Pilot License; MECIR, Multi Engine Command Instrument Rating; MCC, Multi-Crew Cooperation).

Table 1

Responses to Safety Reporting Culture-related items.

\begin{tabular}{lccccccc}
\hline \multicolumn{1}{c}{ Item } & Strongly agree & Agree & $\begin{array}{c}\text { Neither agree nor } \\
\text { disagree }\end{array}$ & Disagree & $\begin{array}{c}\text { Strongly } \\
\text { disagree }\end{array}$ & Mean & SD \\
\hline 36. Report will be looked & 23 & 41 & 30 & 6 & 3 & 2.27 & 0.97 \\
37. Actions will be taken & 14 & 54 & 23 & 9 & 3 & 2.35 \\
39. Report to instructor & 23 & 64 & 12 & 2 & 2 & 1.99 \\
40. Report to dispatch & 10 & 46 & 28 & 11 & 8 & 0.77 \\
35. Report others & 7 & 29 & 40 & 19 & 7 & 2.62 \\
41. Report to CFI & 2 & 22 & 32 & 14 & 12 & 3.06 \\
34. Self-report & 13 & 45 & 26 & 5 & 2.54 & 1.01 \\
\hline
\end{tabular}

In the final analysis, using the unweighted extraction method with a promax rotation, the rotated solution revealed the presence of a simple structure, with all four factors showing a number of strong loadings and all variables loading substantially on only one factor. The four-factor solution explained a total of $51.83 \%$ of the variance, with factor 1 contributing $30.91 \%$, factor 2 contributing $10.41 \%$, factor 3 contributing $5.98 \%$, and factor 4 contributing $4.53 \%$. These factors were named Safety Reporting Culture, Safety Reporting Procedure, Organizational Culture and Practice, and General Safety Knowledge. Furthermore, the reliability of each factor (as evident by the internal consistency of the items constituting each factor) was found to be adequate, with Cronbach's alphas of $0.85,0.83,0.69$, and 0.78 , respectively.

\section{Safety Themes}

\section{Safety Reporting Culture}

The theme Safety Reporting Culture includes seven survey items, which are Q36, Q37, Q39, Q40, Q35, Q41, and Q34. See Table 1 for details. This theme measures the confidence that students have in the safety reporting scheme of the flight training academy, and if they feel comfortable to use this scheme to report a safety matter whenever needed.
Reponses to items under the Safety Reporting Culture theme were mostly skewed to the positive side, with the exception of Q41. Of the six positively responded items, Q39 received the most favorable responses, indicating a generally positive safety climate as well as a good relationship between student pilots and their instructors. On the other hand, the slightly negative responses to Q41 demonstrate the power distance within the training academy: students in general do not feel comfortable approaching the senior management or the chief flying instructor (CFI).

\section{Safety Reporting Procedure}

The theme Safety Reporting Procedure includes five survey items, which are Q33, Q32, Q38, Q31, and Q25. See Table 2 for details. This theme measures the knowledge of students in reporting a safety matter to the flight training academy and handling emergency situations during training.

Reponses to items under the Safety Reporting Procedure theme were mixed. Survey participants, on the one hand, indicated that they were aware of the standard safety reporting policy and were confident in handling an emergency situation. On the other hand, their responses showed moderate confusion in the details of the safety reporting procedure, such 
Table 2

Responses to Safety Reporting Procedure-related items.

\begin{tabular}{|c|c|c|c|c|c|c|c|}
\hline Item & Strongly agree & Agree & $\begin{array}{c}\text { Neither agree nor } \\
\text { disagree }\end{array}$ & Disagree & $\begin{array}{l}\text { Strongly } \\
\text { disagree }\end{array}$ & Mean & SD \\
\hline 33. Know reporting process & 11 & 17 & 36 & 32 & 7 & 3.07 & 1.09 \\
\hline 32. Understand reporting policy & 16 & 31 & 27 & 20 & 8 & 2.74 & 1.18 \\
\hline 38. Where to report & 7 & 23 & 26 & 36 & 11 & 3.20 & 1.11 \\
\hline 31. Awareness of policy & 34 & 43 & 11 & 10 & 5 & 2.12 & 1.12 \\
\hline 25. Can handle emergency & 27 & 68 & 7 & 1 & 0 & 1.83 & 0.58 \\
\hline
\end{tabular}

Table 3

Responses to Organizational Culture and Practice-related items.

\begin{tabular}{|c|c|c|c|c|c|c|c|}
\hline Item & Strongly agree & Agree & $\begin{array}{c}\text { Neither agree nor } \\
\text { disagree }\end{array}$ & Disagree & $\begin{array}{l}\text { Strongly } \\
\text { disagree }\end{array}$ & Mean & SD \\
\hline 26. Positive culture in students & 15 & 62 & 22 & 3 & 1 & 2.16 & 0.74 \\
\hline 27. Positive culture in academy & 31 & 48 & 15 & 4 & 5 & 2.07 & 1.02 \\
\hline 24. Trust other students & 3 & 47 & 34 & 17 & 2 & 2.69 & 0.85 \\
\hline 18. Research CASA regulations & 8 & 21 & 45 & 22 & 7 & 2.99 & 1.00 \\
\hline
\end{tabular}

Table 4

Responses to General Safety Knowledge-related items.

\begin{tabular}{lccccc}
\multicolumn{1}{c}{ Item } & Strongly agree & Agree & $\begin{array}{c}\text { Neither agree nor } \\
\text { disagree }\end{array}$ & $\begin{array}{c}\text { Disagree } \\
\text { Strongly } \\
\text { disagree }\end{array}$ & $\begin{array}{c}\text { Mean } \\
\text { 12. Understand I.M.S.A.F.E. }\end{array}$ \\
13. Apply I.M.S.A.F.E. & 58 & 39 & 4 & 0 & 1.51 \\
14. Alcohol policy & 53 & 38 & 8 & 0.67 & 0 \\
\hline
\end{tabular}

as where to hand in an incident report, which called for the attention of the academy.

\section{Organizational Culture and Practice}

The theme Organizational Culture and Practice includes four survey items, which are Q26, Q27, Q24, and Q18. See Table 3 for details. This theme was designed to measure students' perceptions of the safety culture of the flight training academy. All four survey items received positive to neutral responses, which is a positive sign to the senior management of the academy: students do perceive a positive culture within the academy, and have confidence in their peers as well.

\section{General Safety Knowledge}

The theme General Safety Knowledge includes three survey items, which are Q12, Q13, and Q14. See Table 4 for details. This theme was simply used to test if student pilots understood the detailed safety policy of the training academy. Survey results reported quite highly on this theme, which once again demonstrated the positive culture among students on the execution level.

\section{The Effect of Flying Experience}

In order to test if flying experience has any effect on students' perceptions of safety climate, a one-way between- groups MANOVA was performed on four safety themes between students of different flying hours. Participants were divided into two groups with the reference hours of 75 so that sizes of groups would be relatively balanced. Four safety themes were used as dependent variables in the test. Preliminary assumption testing was conducted to check for normality, linearity, univariate and multivariate outliers, homogeneity of variance-covariance matrices, and multicollinearity, with no violations observed.

Results of the MANOVA did not reveal any significant difference between students who had 75 hours or less flying experience and those who had more than 75 hours across any of the safety themes (Wilks' lambda $=0.93, F(4,96)=1.84$, $p=0.127$ ). The reported mean scores shown in Table 5 across the safety themes were very similar between the two groups, suggesting that flying experience measured by hours has no effect on participants' perceptions of safety climate.

\section{The Effect of Year Groups}

A one-way between-groups MANOVA was also performed to investigate whether year groups would influence participants' perceptions of the safety climate of the flight training academy. First-year students were compared with students from the second and third years so that sizes of groups were comparable. This division also has practical values as students in general are flying for their private pilot 
Table 5

Comparison of safety themes between students of different flying experiences $(N=103)$.

\begin{tabular}{|c|c|c|c|c|}
\hline & \multicolumn{2}{|c|}{$\begin{array}{l}75 \text { hours or less of flying } \\
\text { experience }(n=47)\end{array}$} & \multicolumn{2}{|c|}{$\begin{array}{l}\text { More than } 75 \text { hours of flying } \\
\text { experience }(n=56)\end{array}$} \\
\hline & Mean & $S D$ & Mean & $S D$ \\
\hline Safety Reporting Culture & 2.48 & 0.61 & 2.65 & 0.77 \\
\hline Safety Reporting Procedure & 2.51 & 0.71 & 2.69 & 0.86 \\
\hline Organizational Culture and Practice & 2.30 & 0.59 & 2.62 & 0.69 \\
\hline General Safety Knowledge & 1.52 & 0.52 & 1.41 & 0.59 \\
\hline
\end{tabular}

Table 6

Comparison of safety themes between students of different year groups $(N=101)$.

\begin{tabular}{lccccc}
\hline & \multicolumn{2}{c}{ Year 1 $(\boldsymbol{n}=\mathbf{4 7})$} & & \multicolumn{2}{c}{ Years 2 and 3 $(\boldsymbol{n}=\mathbf{5 4})$} \\
\cline { 2 - 3 } \cline { 5 - 6 } & Mean & SD & & Mean & SD \\
\hline Reporting Culture & 2.40 & 0.58 & 2.72 & 0.77 \\
Reporting Procedure $_{\text {Organizational Culture and Practice }}^{\mathrm{a}}$ & 2.47 & 0.67 & & 2.73 & 0.88 \\
General Safety Knowledge $^{\mathrm{a}}$ & 2.23 & 0.56 & & 2.69 & 0.68 \\
\hline
\end{tabular}

${ }^{a}$ Significant difference in mean score between the groups.

license in the first year, and will work on their commercial pilot license in the second and third years of study.

Similarly, four safety themes identified in the factor analysis were used as dependent variables in the MANOVA. Preliminary assumption testing was conducted to check for normality, linearity, univariate and multivariate outliers, homogeneity of variance-covariance matrices, and multicollinearity. With the exception of the homogeneity of variance-covariance assumption being violated, no other serious violations were noted. Consequently rather than reporting Wilks' lambda, Pillai's criterion is reported as it is less sensitive to violations of assumptions and therefore more robust (Tabachnick \& Fidell, 2007). Results revealed a significant difference in participants' perceptions toward the four safety themes between the year groups (Pillai's trace $=$ $0.14 ; F(4,96)=3.83, p<0.01$, partial $\eta^{2}=0.14$ ).

Univariate tests revealed there was a significant difference in the mean scores between the groups for Reporting Culture $\left(F(1,99)=5.59, p=0.02\right.$, partial $\left.\eta^{2}=0.05\right)$. First-year students reported significantly lower scores, on average, than second- and third-year students. Similarly, for Organizational Culture and Practice, first-year students reported significantly more favorable responses than secondand third-year students $(F(1,99)=13.66, p<0.001$, partial $\eta^{2}=0.12$ ). Meanwhile, no significant differences were found in the mean scores between the groups for either Reporting Procedure $(F(1,99)=2.86, p=0.094)$ or General Safety Knowledge $(F(1,99)=0.75, p=0.389)$. See Table 6 for details.

\section{Conclusions}

Findings of this study suggest that students' perceptions of the safety climate of the flight training academy, mea- sured by four safety themes identified through factor analysis, were mostly positive. Participants' responses to survey items indicated that they have confidence in the safety reporting system and feel comfortable to report a safety matter when needed. Students believe in the safety culture of the training academy. In terms of operations, students understand the details of safety policy, and are relatively knowledgeable of the safety reporting policy.

Of the four safety themes, General Safety Knowledge received the most positive responses, indicating the successful safety education, and in particular safety policy education, provided by the academy. This is largely attributed to the professional environment and to the well-functioning corporate structure of the training academy. On the other hand, survey results also revealed issues that required further improvements, e.g. the power distance between students and senior management, and students' understating of the details of the safety reporting procedures.

The test on the effect of experience measured by flight hours did not result in any significance difference, suggesting hours would not shape students' perceptions of the safety climate. However, considering the sample of this study was formed by student pilots in their very early stages of flight training, the range of their experiences may not be wide enough to cast a significant impact on their perceptions of the safety climate.

The effect of year groups was found to be significant on participants' responses to survey items related to Reporting Culture as well as Organizational Culture and Practice. First-year students in general were more positive in terms of their perceptions of the safety climate than students of the second and third years. This finding confirms the previous study by Adjekum (2014), which found there was a significant effect of year groups on the perception of 
safety culture in an American collegiate aviation program. It also supports similar studies conducted in the airline environment where junior flight crew perceived a more positive safety climate than their senior colleagues (Gao et al., 2013; Gao, Bruce, \& Rajendran, 2015). Compared with the effect of training experience measured by flight hours, which was not found to be significant, it is worth noting that in a tertiary aviation program, students' learning and teaching activities are organized by year groups. Year group affiliation is more likely to shape students' view towards safety than flying hours. Therefore, it is worthwhile to organize formal and informal activities more often to mingle students of different year groups in order to share enthusiasm, experiences, and culture vertically. Such activities could include theory tutorials taught by senior students and social events organized by the aviation student society.

The sample of this study came from only one aviation program, and the sample size was limited. Therefore, findings of this study should not be generalized to other aviation programs before further analysis. The value of this study lies in its investigation progress which could be easily adopted by other flight schools. Also, results of this study could be used as a benchmark to assess other similar organizations.

This study only captured a "snapshot" of students' perception of the safety climate of the flight training academy at the moment when the survey was conducted. Though the effect of year groups was found to be significant, it is not clear if the difference between year groups was caused by the flight training course, or by the selection of students at different years. In other words, this study is unable to tell if experience with the flight training program will shape a student's safety perception. Therefore, it is recommended that a longitudinal study follows the same groups of students for the duration of their studies using the same survey instrument to address this issue.

\section{References}

Adjekum, D. K. (2014). Safety culture perceptions in a collegiate aviation program: A systematic assessment. Journal of Aviation Technology and Engineering, 3(2), 44-56.

Adjekum, D. K., Keller, J., Walala, M., Young, J. P., Christensen, C., DeMik, R. J., \& Northam, G. J. (2015). Cross-sectional assessment of safety culture perceptions and safety behavior in collegiate aviation programs in the United States. International Journal of Aviation, Aeronautics, and Aerospace, 2(4), article 3.

Barlett, M. S. (1954). A note on the multiplying factors for various chi square approximations. Journal of the Royal Statistical Society, 16 (Series B), 296-298.

Catell, R. B. (1966). The scree test for number of factors. Multivariate Behavioral Research, 1, 245-276.

Ek, Å., \& Akselsson, R. (2007). Aviation on the ground: Safety culture in a ground handling company. International Journal of Aviation Psychology, 17(1), 59-76.

Ek, Å., Akselsson, R., Arvidsson, M., \& Johansson, C. R. (2007). Safety culture in Swedish air traffic control. Safety Science, 45(7), 791-811.
Freiwald, D., Lenz-Anderson, C., \& Baker, E. (2013). Assessing safety culture within a flight training organization. Journal of Aviation/ Aerospace Education and Research, 22(2).

Gao, Y., Bruce, P. J., Newman, D. G., \& Zhang, C. B. (2013). Safety climate of commercial pilots: The effect of pilot ranks and employment experiences. Journal of Air Transport Management, 30, 17-24. http:// dx.doi.org/10.1016/j.jairtraman.2013.04.001

Gao, Y., Bruce, P. J., \& Rajendran, N. (2015). Safety climate of a commercial airline: A cross-sectional comparison of four occupational groups. Journal of Air Transport Management, 47(C), 162-171.

Kaiser, H. (1970). A second generation little jiffy. Psychometrika, 35(4), 401-415.

Kaiser, H. (1974). An index of factorial simplicity. Psychometrika, 39(1), 31-36.

Kao, L. H., Stewart, M., \& Lee, K. H. (2009). Using structural equation modeling to predict cabin safety outcomes among Taiwanese airlines. Transportation Research Part E: Logistics and Transportation Review, 45(2), 357-365.

Niskanen, T. (1994). Safety climate in the road administration. Safety Science, 17(4), 237-255.

Tabachnick, B. G., \& Fidell, L. S. (2007). Using multivariate statistics. Boston, MA: Pearson.

Varonen, U., \& Mattila, M. (2000). The safety climate and its relationship to safety practices, safety of the work environment and occupational accidents in eight wood-processing companies. Accident Analysis and Prevention, 32(6), 761-769.

Wiegmann, D. A., Zhang, H., von Thaden, T., Sharma, G., \& Mitchell, A. (2002). A synthesis of safety culture and safety climate research. Retrieved from https://www.nrc.gov/docs/ML1025/ML102500649.pdf

\section{Appendix A - Survey Instrument}

\section{Part I. Demographics}

1. Gender $\square$ Male $\square$ Female

2. Age $\square$ 18-19 $\square$ 20-22 $\square$ 23-25 $\square$ Over 25

3. Course $\square$ Bachelor of aviation

Bachelor of aviation/business

Associate degree
4. Year group $\square$ Year $1 \square$ Year $2 \square$ Year 3 Year 4

5. Total flying hours $\square$ Under $25 \square$ 26-50 $\square$ 51-75 $\square$ Over 75

6. License/rating $\square$ RPL $\square$ PPL $\square$ CPL $\square$ MECIR $\mathrm{MCC}$

Part II. Please indicate if you agree or disagree with the following statements, using the scale below ranging from "strongly agree" to "strongly disagree":

7. I read the Flight Safety Publications provided electronically by CASA.

8. I pay attention to any notices or posters that related to safety when I am at the training academy.

9. I am conscious of my physical and mental wellbeing and how it will affect my flight performance. 
10. I will not perform any flight if I feel the outside pressure or stress that may affect my flight performance.

11. I always check with DAME when I have to take any medication for any reason.

12. I understand the acronym I.M.S.A.F.E.

13. I know how to apply I.M.S.A.F.E, in regards to flight safety.

14. I understand the policy of alcohol consumption before flying.

15. I always make sure that I have enough sleep/rest before my flight lesson.

16. I always take necessary pre-flight planning steps to ensure that I am fully prepared for my flight. (e.g. Seeking help from your instructor if needed, allowing sufficient time to plan for your level of training etc.)

17. I always arrive earlier than required to allow sufficient time to pre-flight and mentally prepare for my flight.

18. My instructor encourages me to research more about CASA regulations and procedures to maintain safe practice whilst flying.

19. At the completion of the flight, I carry out the proper shut down procedure according to the checklist with proper read back requirements.

20. I am more comfortable seeking help from my colleagues instead of my instructors for safety related issues.

21. I am aware of latest policy/procedure changes (FIFs) that are on the system of the training academy that may affect safety.

22. I confirm the FIFs without fully reading and understanding them.

23. As a flight student, I am familiar with the appropriate CASA procedures and documentation associated with my flight training.

24. I believe that other students take all safety policies and standard operating procedures seriously.
25. I believe I have adequate knowledge to handle an emergency situation (forced landings, inversion, precautionary search etc.) that may happen in my flight training.

26. I believe there is a positive safety culture amongst student pilots.

27. I believe that the training academy has a positive safety culture.

28. My instructor follows the SOPs as what has been taught during the flight briefing in regards to safety.

29. Whilst on a flight, my instructor abides by the applicable VMC separation and regulations.

30. During my flight training, I understand that issues influencing safety should be reported to the training academy immediately.

31. I am aware that there is a standard safety reporting policy of the training academy.

32. I understand the standard safety reporting policy of the training academy.

33. I know the process of safety reporting when I have to report any safety issues to the training academy.

34. I feel comfortable to report a safety related issue that I was involved in.

35. I feel comfortable to report a safety related issue that other students were involved in.

36. If I report a safety related issue, I am confident that my issue will be looked at.

37. I am confident that action will be taken in reference to my issue, and resolved so it can be avoided in the future.

38. I know where to place the written incident report once completed.

39. If a problem occurs during my flight training, I feel comfortable reporting it to my instructor.

40. If a problem occurs during my flight training, I feel comfortable reporting it to the dispatch of the training academy.

41. If a problem occurs during my flight training, I feel comfortable reporting it to senior management/the chief flying instructor $(\mathrm{CFI})$. 


\section{Appendix B - Exploratory Factor Analysis}

Table 7

Pattern matrix.

\begin{tabular}{|c|c|c|c|c|}
\hline & \multicolumn{4}{|c|}{ Factor } \\
\hline & 1 & 2 & 3 & 4 \\
\hline Q36 If I report a safety-related issue, I am confident that my issue will be looked at. & 0.851 & 0.121 & -0.288 & 0.115 \\
\hline $\begin{array}{l}\text { Q37 I am confident that action will be taken in reference to my issue, and resolved so it can be } \\
\text { avoided in the future. }\end{array}$ & 0.805 & 0.024 & 0.010 & 0.186 \\
\hline Q39 If a problem occurs during my flight training, I feel comfortable reporting it to my instructor. & 0.626 & -0.119 & 0.233 & 0.028 \\
\hline $\begin{array}{l}\text { Q40 If a problem occurs during my flight training, I feel comfortable reporting it to the dispatch of } \\
\text { the training academy. }\end{array}$ & 0.588 & -0.211 & 0.266 & -0.134 \\
\hline Q35 I feel comfortable to report a safety related issue that other students were involved in. & 0.531 & 0.286 & -0.169 & -0.121 \\
\hline $\begin{array}{l}\text { Q41 If a problem occurs during my flight training, I feel comfortable reporting it to senior } \\
\text { management/the chief flying instructor (CFI). }\end{array}$ & 0.495 & 0.075 & 0.103 & -0.115 \\
\hline Q34 I feel comfortable to report a safety related issue that I was involved in. & 0.479 & 0.245 & 0.006 & -0.097 \\
\hline Q33 I know the process of safety reporting when I have to report any safety issues at the training academy. & -0.201 & 0.948 & 0.095 & -0.009 \\
\hline Q32 I understand the standard safety reporting policy of the training academy. & 0.061 & 0.726 & 0.168 & -0.030 \\
\hline Q38 I know where to place the written incident report once completed. & 0.186 & 0.519 & -0.027 & -0.072 \\
\hline Q31 I am aware that there is a standard safety reporting policy of the training academy. & 0.173 & 0.459 & 0.273 & 0.002 \\
\hline $\begin{array}{l}\text { Q25 I believe I have adequate knowledge to handle an emergency situation (forced landings, } \\
\text { inversion, precautionary search etc.) that may happen in my flight training. }\end{array}$ & 0.140 & 0.459 & -0.103 & 0.205 \\
\hline Q26 I believe there is a positive safety culture amongst student pilots. & 0.004 & 0.071 & 0.722 & 0.027 \\
\hline Q27 I believe that the training academy has a positive safety culture. & 0.263 & -0.085 & 0.682 & -0.007 \\
\hline Q24 I believe that other students take all safety policies and standard operating procedures seriously. & -0.176 & 0.112 & 0.504 & 0.014 \\
\hline $\begin{array}{l}\text { Q18 My instructor encourages me to research more about CASA regulations and procedures to } \\
\text { maintain safe practice whilst flying. }\end{array}$ & 0.043 & 0.072 & 0.384 & 0.136 \\
\hline Q12 I understand the acronym I.M.S.A.F.E. & -0.046 & -0.017 & 0.071 & $\mathbf{0 . 9 3 3}$ \\
\hline Q13 I know how to apply I.M.S.A.F.E, in regards to flight safety. & -0.004 & 0.021 & 0.038 & 0.845 \\
\hline Q14 I understand the policy of alcohol consumption before flying. & 0.073 & 0.015 & -0.001 & 0.454 \\
\hline
\end{tabular}

Note. Extraction method: unweighted least squares. Rotation method: promax with Kaiser normalization. (Rotation converged in 7 iterations.)

Table 8

Structure matrix.

\begin{tabular}{|c|c|c|c|c|}
\hline & \multicolumn{4}{|c|}{ Factor } \\
\hline & 1 & 2 & 3 & 4 \\
\hline $\begin{array}{l}\text { Q37 I am confident that action will be taken in reference to my issue, and resolved so it can be avoided in the } \\
\text { future. }\end{array}$ & 0.811 & 0.462 & 0.481 & 0.129 \\
\hline Q36 If I report a safety-related issue, I am confident that my issue will be looked at. & 0.744 & 0.464 & 0.248 & 0.051 \\
\hline Q39 If a problem occurs during my flight training, I feel comfortable reporting it to my instructor. & 0.692 & 0.319 & 0.542 & -0.012 \\
\hline $\begin{array}{l}\text { Q40 If a problem occurs during my flight training, I feel comfortable reporting it to the dispatch of } \\
\text { the training academy. }\end{array}$ & 0.634 & 0.225 & 0.515 & -0.169 \\
\hline Q34 I feel comfortable to report a safety related issue that I was involved in. & 0.623 & 0.514 & 0.382 & -0.140 \\
\hline $\begin{array}{l}\text { Q41 If a problem occurs during my flight training, I feel comfortable reporting it to senior management/the } \\
\text { chief flying instructor (CFI). }\end{array}$ & 0.604 & 0.393 & 0.418 & -0.153 \\
\hline Q35 I feel comfortable to report a safety related issue that other students were involved in. & 0.600 & 0.511 & 0.254 & -0.168 \\
\hline Q33 I know the process of safety reporting when I have to report any safety issues at the training academy. & 0.373 & 0.877 & 0.372 & -0.030 \\
\hline Q32 I understand the standard safety reporting policy of the training academy. & 0.557 & 0.830 & 0.503 & -0.062 \\
\hline Q31 I am aware that there is a standard safety reporting policy of to the dispatch of the training academy. & 0.580 & 0.667 & 0.561 & -0.028 \\
\hline Q38 I know where to place the written incident report once completed. & 0.460 & 0.613 & 0.295 & -0.104 \\
\hline $\begin{array}{l}\text { Q25 I believe I have adequate knowledge to handle an emergency situation (forced landings, inversion, } \\
\text { precautionary search etc.) that may happen in my flight training. }\end{array}$ & 0.317 & 0.485 & 0.166 & 0.179 \\
\hline Q27 I believe that the training academy has a positive safety culture. & 0.607 & 0.341 & 0.797 & -0.024 \\
\hline Q26 I believe there is a positive safety culture amongst student pilots. & 0.454 & 0.370 & 0.753 & 0.022 \\
\hline Q24 I believe that other students take all safety policies and standard operating procedures seriously. & 0.172 & 0.223 & 0.449 & 0.021 \\
\hline $\begin{array}{l}\text { Q18 My instructor encourages me to research more about CASA regulations and procedures to } \\
\text { maintain safe practice whilst flying. }\end{array}$ & 0.292 & 0.249 & 0.438 & 0.129 \\
\hline Q12 I understand the acronym I.M.S.A.F.E. & -0.081 & -0.047 & 0.034 & 0.937 \\
\hline Q13 I know how to apply I.M.S.A.F.E, in regards to flight safety. & -0.030 & 0.004 & 0.042 & 0.844 \\
\hline Q14 I understand the policy of alcohol consumption before flying. & 0.048 & 0.038 & 0.045 & 0.449 \\
\hline
\end{tabular}

Note. Extraction method: unweighted least squares. Rotation method: promax with Kaiser normalization. 
Table 9

Factor correlation matrix.

\begin{tabular}{lrrrr}
\hline Factor & $\mathbf{1}$ & $\mathbf{2}$ & $\mathbf{3}$ & $\mathbf{4}$ \\
\hline 1 & 1.000 & 0.548 & 0.572 & -0.071 \\
2 & 0.548 & 1.000 & 0.413 & -0.036 \\
3 & 0.572 & 0.413 & 1.000 & -0.003 \\
4 & -0.071 & -0.036 & -0.003 & 1.000 \\
\hline
\end{tabular}

Note. Extraction method: unweighted least squares.

Rotation method: promax with Kaiser normalization.

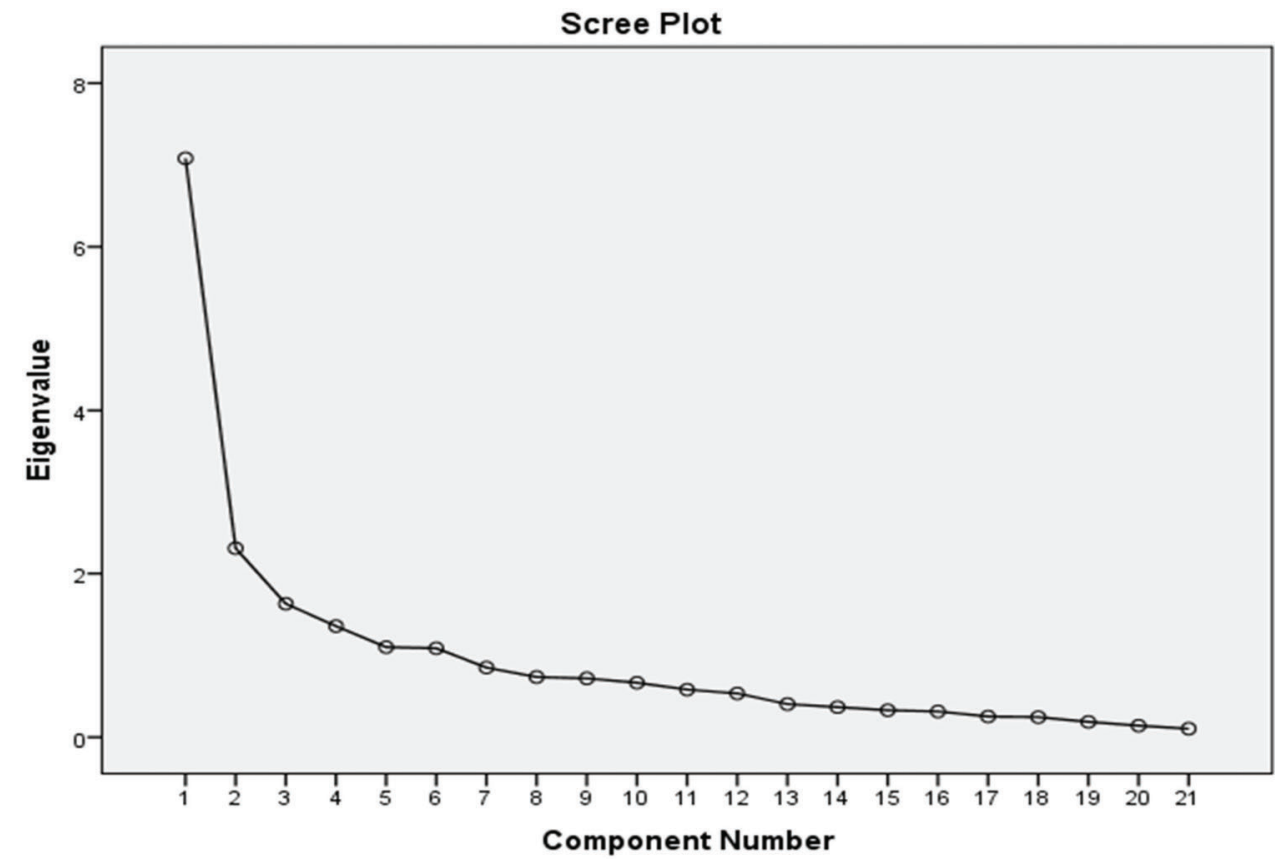

Figure 3. Scree plot.

Dr Yi Gao received his $\mathrm{PhD}$ in aviation management from Purdue University. $\mathrm{He}$ is currently the Aviation Course Director for the Department of Aviation, Faculty of Science, Engineering and Technology, Swinburne University of Technology. As a researcher, his principal research areas include airline operations optimization, aviation safety, pilot selection, and pilot learning/cognitive styles.

Natalia Rajendran is currently a $\mathrm{PhD}$ candidate at Monash University in Melbourne, Australia. She holds an MS degree in applied statistics and an honors degree in psychology both from Swinburne University, a BA and a post-graduate diploma in criminology from the University of Melbourne, and a post-graduate diploma in education from the University of Sydney. Her primary research areas of interest are in safety, health, and well-being. 